\title{
A case of tropical pulmonary eosinophilia after elimination of lymphatic filariasis in Sri Lanka
}

\author{
*V P Sinhabahu ${ }^{1}$, T M R Perera ${ }^{2}$, M H M Nazmy ${ }^{3}$, M S T Guruge ${ }^{3}$, J Hettiarachchi ${ }^{3}$ \\ Sri Lanka Journal of Child Health, 2018; 47(4): 354-356 \\ DOI: http://dx.doi.org/10.4038/sljch.v47i4.8599 \\ (Key words: Eosinophilia, lymphatic filariasis, tropical pulmonary eosinophilia)
}

\section{Case report}

A previously healthy seven year old girl presented with on and off fever and cough of one month duration in September 2016. Cough was worse in the night without associated wheezing. She was the third child of healthy non consanguineous parents with two healthy siblings. There was no history of joint symptoms, atopy or asthma. Examination revealed an averagely built active child with generalized lymphadenopathy. Largest lymph node was in the right axilla measuring $2.5 \mathrm{~cm} \times 2.5 \mathrm{~cm}$. Her BCG scar was absent. Ears and throat were normal.

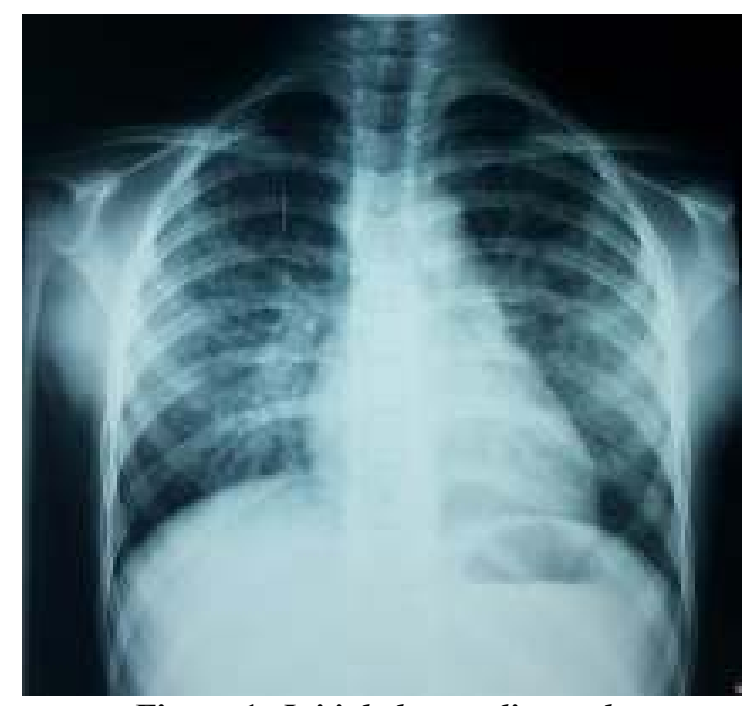

Figure 1: Initial chest radiograph

${ }^{1}$ Senior Registrar in Paediatrics, ${ }^{2}$ Senior Lecturer and Consultant Paediatrician, ${ }^{3}$ Registrar in Paediatrics, Professorial Paediatric Unit, Colombo South Teaching Hospital, Kalubowila.

*Correspondence: sinbad.1k@gmail.com

(Received on 30 January 2017: Accepted after revision on 17 March 2017)

The authors declare that there are no conflicts of interest

Personal funding was used for the project.

Open Access Article published under the Creative

Commons Attribution CC-BY (CC)
There was no hepatosplenomegaly or bone tenderness. Bilateral occasional crepitations were present on auscultation. Cardiovascular and central nervous system examinations were normal. Chest radiograph revealed bilateral interstitial shadows without consolidations and hilar lymphadenopathy (Figure 1)

Ultrasound scan of the abdomen ruled out intraabdominal lymphadenopathy and organomegaly. Stool examination did not show evidence of worm infestation making Loffler syndrome unlikely. Mantoux test, toxocara antibodies, toxoplasma IgM antibodies and filarial antibody test (FAT) for IgG antibodies, done on day 1 of admission were negative. Full blood count, erythrocyte sedimentation rate (ESR), lactate dehydrogenase (LDH) and C-reactive protein (CRP) are shown in table 1

As the child had severe eosinophilia, liver, renal function tests and 2D echocardiography were done to assess end organ damage and they were found to be normal. Blood pictures done on days $01,06,10$, 29 and 51 showed mature eosinophils without abnormal cells or blasts. Night blood film did not show microfilariae on day 5. Wuchereria bancrofti antigen was negative on day 5 . Repeat FAT done on day 5 and day 18 were negative.

Child was treated with albendazole for 14 days as our first differential diagnosis was visceral larva migrans. Although 23\% reduction in eosinophil count was seen after five days of treatment, subsequent rise in eosinophil count made the diagnosis of visceral larva migrans unlikely. Child was started on diethylcarbamazine (DEC) $3 \mathrm{mg} / \mathrm{kg}$ on day 6 and this was continued for 5 weeks to treat as tropical pulmonary eosinophilia. Marked reduction in eosinophilia was seen with treatment with DEC. Symptoms improved and lymphadenopathy resolved with DEC treatment with rapid reduction in eosinophilia. After 21 days of treatment, chest $\mathrm{x}$-rays showed improvement (Figure 2). 
Table 1: Summary of investigations

\begin{tabular}{|l|c|c|c|c|c|c|c|c|c|}
\hline $\begin{array}{l}\text { Day from hospital } \\
\text { admission }\end{array}$ & $\mathbf{0 1}$ & $\mathbf{0 4}$ & $\mathbf{0 6}$ & $\mathbf{1 0}$ & $\mathbf{1 3}$ & $\mathbf{1 6}$ & $\mathbf{2 9}$ & $\mathbf{5 1}$ & $\mathbf{8 0}$ \\
\hline White count / cu mm & 50,760 & 32,900 & 38,670 & 20,280 & 11,610 & 6,310 & 8,620 & 7,890 & 4,500 \\
\hline Eosinophils / cu mm & 36,180 & 23,900 & 27,730 & 12,170 & 5,340 & 700 & 1,660 & 1100 & 256 \\
& $(72.5 \%)$ & $(72.5 \%)$ & $(71.7 \%)$ & $(60 \%)$ & $46 \%)$ & $(11.1 \%)$ & $(19.2 \%)$ & $(14 \%)$ & $(5.7 \%)$ \\
\hline Neutrophils /cu mm & 4,520 & 4,270 & 2,860 & 1,220 & 3,630 & 950 & 1,810 & 2,840 & 2,450 \\
& $(8.9 \%)$ & $(13 \%)$ & $(7.4 \%)$ & $(6 \%)$ & $(31.3 \%)$ & $(15 \%)$ & $(21 \%)$ & $(36 \%)$ & $(54.5 \%)$ \\
\hline Lymphocytes / cu mm & 8,480 & 4,280 & 7,150 & 5,580 & 1,740 & 4,100 & 4,480 & 3,780 & 1,350 \\
& $(16.7 \%)$ & $(13 \%)$ & $(18.5 \%)$ & $(27.5 \%)$ & $(15 \%)$ & $(65 \%)$ & $(52 \%)$ & $(48 \%)$ & $(30 \%)$ \\
\hline Platelets / cu mm & 319,000 & 348,000 & 449,000 & 353,000 & 260,000 & 348,000 & 415,000 & 289,000 & 264,000 \\
\hline Haemoglobin (g/dl) & 11.7 & 11.1 & 11.5 & 11.4 & 11.8 & 11.9 & 11.6 & 11.7 & 10.8 \\
\hline ESR (mm 1st hour) & 35.0 & & & 50.0 & 65.0 & & & 15.0 & \\
\hline CRP (mg/L) & $<5$ & & & & 14.6 & & & & \\
\hline LDH (U/L) & 584.5 & & & & & & & 428.2 & \\
\hline
\end{tabular}

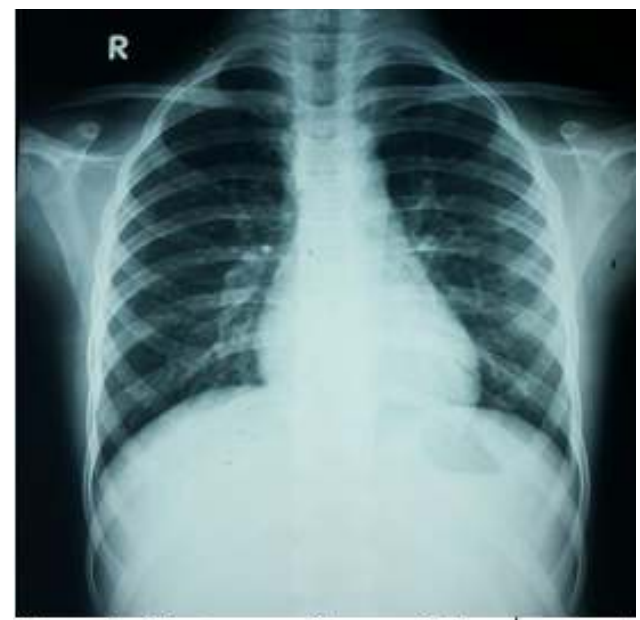

Figure 2: Chest $x$-ray after completing freatment

Lymphadenopathy was subsiding. When reviewed 16 days after the completion of DEC, lymphadenopathy had subsided and the total eosinophil count was $1100 / \mathrm{cu} \mathrm{mm}$. On day 80 of illness, eosinophilia has settled and chest x-ray was normal (Figure 3).

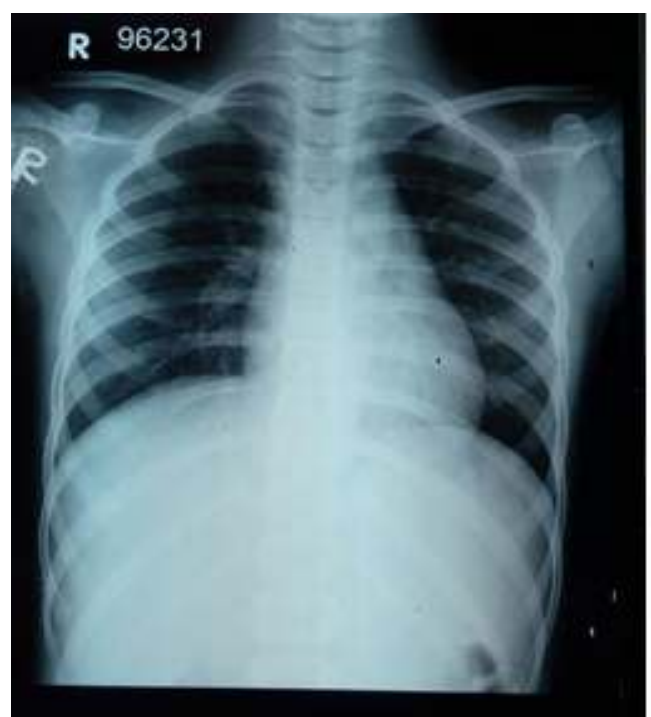

Figure 3: Chest $x$ ray 45 days after completing treatment

\section{Discussion}

Eosinophilic leukaemia, hypereosinophilic syndrome, eosinophilic pneumonia, allergic bronchopulmonary aspergillosis, parasitic infections including tropical pulmonary eosinophilia (TPE) and Loffler syndrome were the differential diagnoses in our patient. High ESR, high eosinophil count and lymphadenopathy were suggestive of a malignancy though the child was clinically well. As the blood picture did not show evidence of a neoplasm, it was decided to treat as for a parasitic disease and assess the response. Steroids were not started as eosinophilic leukaemia was a differential diagnosis. It was decided to clinically follow up the child and do bone marrow examination if indicated.

TPE is an exaggerated immune response to the filarial antigens which includes type I, type III and type IV reactions with eosinophils playing a major role $^{1}$. Criteria for diagnosis of TPE include: (i) history of nocturnal symptoms mainly cough and dyspnoea, (ii) pulmonary infiltrates on chest radiograph, (iii) leucocytosis with peripheral eosinophilia $>3000 / \mathrm{cu} \mathrm{mm}$, (iv) elevated serum IgE and filarial specific $\operatorname{IgG}$ and $\operatorname{IgE}$, (v) peripheral blood specimen that tested negative for microfilariae and (vi) clinical improvement with $\mathrm{DEC}^{1}$. ESR is elevated in $90 \%$ and lymphadenopathy is seen in $\mathrm{TPE}^{1,2}$. Ig E levels could not be done due to financial constrains and unavailability in the government sector.

A study done in Sri Lanka showed that the diagnosis of TPE relied on residing in filarial endemic area, cough worse at night, eosinophil count $>3300 / \mathrm{cu} \mathrm{mm}$, clinical and haematological response to $\mathrm{DEC}^{3}$. Diagnosis is supported by elevated ESR in $80 \%$ and chest radiograph changes in $45.5 \%$ but FAT was positive only in $30 \%{ }^{3}$. In May 2016 the WHO officially declared that Sri Lanka was free of filariasis having brought the microfilariae rate (MFR) to less than $1 \%{ }^{4}$. The MFR was $0.004 \%$ in the Colombo district in $2015^{5}$. 
Our patient adds to the wide range of filariasis in our region. Our patient showed a marked therapeutic response to DEC treatment which was supportive of the diagnosis. Although Sri Lanka has very low MFR and is declared as filarial free, TPE should be considered in the differential diagnosis of eosinophilia.

\section{Acknowledgements}

We acknowledge the support given by Dr. C. Moonasinghe, Consultant Haematologist, Professor Deepika Fernando, Consultant Parasitologist and the antifilaria campaign in managing our patient.

\section{References}

1. Mullerpattan JB, Udwadia ZF, Udwadia FE. Tropical pulmonary eosinophilia - A review. The Indian Journal of Medical Research 2013; 138(3):295-302.

PMid: 24135173 PMCid: PMC3818591

2. Keystone JS, Boggild AK, Kain KC. Tropical pulmonary eosinophilia: A case series in a setting of non-endemicity. Clinical Infectious Disease 2004; 39(8): 1123-8

https://doi.org/10.1086/423964

PMid: 15486834
3. Cooray JHL, Ismail MM. Re-examination of diagnostic criteria for tropical pulmonary eosinophilia. Respiratory Medicine 1999; 99: 655-9. https://doi.org/10.1016/S09546111(99)90 106-3

4. WHO officially declares Sri Lanka filariasis free. WHO press release. Accessed from: http://www.searo.who.int/srilanka/docume nts/WHO officially declares Sri Lanka filariasis_free/en/ on 2016.12.11

5. Microfilaria rate in Colombo District (2005 - 2015). Antifilariasis campaign. Accessed from:

http://www.filariasiscampaign.health.gov.l k/subpgs/03_reports.html on 2016.11.16 